\title{
Susceptibility Pattern of Neisseria gonorrhoeae towards Cefixime and Ceftriaxone using Kirby-Bauer Method in Dr. Saiful Anwar General Hospital Malang
}

\author{
Lita Setyowatie, Tantari SHW, Inneke Yulian \\ Department Dermatology and Venereology, Faculty of Medicine, University of Brawijaya /Dr. Saiful \\ Anwar General Hospital, Malang, Indonesia
}

\begin{abstract}
Background: Gonorrhea remains the second most common sexually transmitted infection (STI) in the world with an increasing number of cases. Oral cefixime and IM ceftriaxone are still the mainstay therapy for gonorrhea in Indonesia. However, previous studies suggested possible resistance to ceftriaxone and cefixime, which are the first-line treatment of gonorrhea. To date, there are no data available regarding the susceptibility of these antibiotics for the treatment of gonorrhea in Dr. Saiful Anwar General Hospital (RSSA) Malang. Purpose: Determine susceptibility pattern of Neisseria gonorrhoeae towards cefixime and ceftriaxone in RSSA Malang. Methods: The samples were patients of the Outpatient Clinic of Dermatology and Venereology Department with a symptom of discharge which contained Gram-negative diplococcus after Gram staining and had a positive culture of Neisseria gonorrhoeae. Susceptibility testing for cefixime and ceftriaxone antibiotics were performed using the Kirby-Bauer method. The data are presented in percentages. Result: Antibiotic susceptibility test results showed that $80.77 \%$ of Neisseria gonorrhoeae isolates were still susceptible to cefixime, and $80.77 \%$ of isolates were still susceptible to ceftriaxone. Conclusion: Cefixime and ceftriaxone are still effective as gonorrhea therapy in RSSA Malang.
\end{abstract}

Keywords: susceptibility, resistance, cefixime, ceftriaxone.

Correspondence: Lita Setyowatie, Department Dermatology and Venereology, Faculty of Medicine, University of Brawijaya / Dr. Saiful Anwar General Hospital Malang, Jaksa Agung Suprapto St., No. 2 Malang - Indonesia, Phone: +628113393679, e-mail: lita_centik@yahoo.com

\section{BACKGROUND}

Gonorrhea is currently the second most common sexually transmitted infection (STI) in the world. ${ }^{1.2}$ According to the World Health Organization (WHO), there are a total of 106 million cases of gonorrhea infection globally each year. ${ }^{3}$ Incident of gonorrhea in the United States reached 98.1 cases per 100,000 population in 2009. During 2015 - 2016, the prevalence of gonorrhea cases increased by $48.6 \%$ compared to 2009. Incidence of gonorrhea in Southeast Asia is 16.2 per 1,000 females and 37 per 1,000 males, with a prevalence of $0.8 \%$ in females and $1.2 \%$ in males. ${ }^{5}$

Intramuscular (IM) ceftriaxone, a thirdgeneration cephalosporin, is the first-line drug for the treatment of gonorrhea, while oral cefixime oral is no longer recommended by the Centers for Disease Control and Prevention (CDC) in 2015 as the primary choice of therapy for gonorrhea due to numerous reports of resistance. ${ }^{4}$ To date, there is no report from WHO regarding cephalosporin resistance in Indonesia. Several studies conducted in some cities of Indonesia (Semarang, Surabaya, and Denpasar) suggested a decreased susceptibility of cefixime and ceftriaxone. ${ }^{6,7,8}$ Oral cefixime and IM ceftriaxone are still the mainstay therapy of gonorrhea in Indonesia. ${ }^{9}$

Cephalosporin resistance has been increasingly reported. Recent studies in Japan and France found two ceftriaxone resistant strains. ${ }^{10}$ Study by Hananta et al. collected isolates from multiple STI clinics in Jakarta, Yogyakarta, and Denpasar, and they found that the isolates were $100 \%$ susceptible to ceftriaxone and cefixime. ${ }^{6}$ In contrast, a study in Bali showed that $37.9 \%$ of isolates were susceptible to ceftriaxone, and $48.8 \%$ were susceptible to cefixime. ${ }^{7}$ Similar study in Semarang revealed that $77 \%$ of their samples were ceftriaxone-resistant, which means only $23 \%$ were susceptible to ceftriaxone. ${ }^{8}$ This study aims to determine susceptibility pattern of Neisseria gonorrhoeae towards cefixime and ceftriaxone in Dr. Saiful Anwar General Hospital (RSSA) Malang.

\section{METHODS}

The samples were patients who visited the Outpatient Clinic of Dermatology and Venereology Department at RSSA Malang. Inclusion criteria were 
male and female patients with complaints of urethral, cervical, rectal, or conjunctival discharge which contained intracellular or extracellular Gram-negative diplococci upon Gram staining, and those who voluntarily participated as study subjects and signed written informed consent. Female patients who were menstruating, pregnant, or unmarried were excluded from this study.

The sample size of this study was determined to be 26. The data of the previous studies regarding the percentage of Neisseria gonorrhoeae susceptibility to cefixime and ceftriaxone suggested $23 \%$ and $48 \%$, respectively, with $95 \%$ confidence interval, and 0.1 significance level. This study implemented consecutive sampling. This study has been reviewed and granted permission by the Ethics Committee of RSSA Malang.

Antibiotic susceptibility is based on the concept of disruption of microbial life due to an antibiotic. An organism is considered susceptible if the diameter of the inhibition zone is $\geq 35 \mathrm{~mm}$ for ceftriaxone (disc contains $30 \mu \mathrm{g}$ of drug) and $\geq 31 \mathrm{~mm}$ for cefixime (disc contains $5 \mu \mathrm{g}$ of drug). ${ }^{11}$ Antibiotic resistance is based on the concept of no disturbance of microbial life due to an antibiotic. An organism is considered resistant if the diameter of inhibition zone is $<35 \mathrm{~mm}$ for ceftriaxone (disc contains $30 \mu \mathrm{g}$ of drug) and $<31 \mathrm{~mm}$ for cefixime (disc contains $5 \mu \mathrm{g}$ of drug). ${ }^{11}$

Kirby-Bauer method is an antibiotic susceptibility testing method utilizing diffusion technique by placing antibiotic-imbued discs placed in a bacterial colony growing in a culture medium. The diameter of zone of inhibition is then measured using a ruler or calliper. This method was chosen as it was readily available and feasible.

History and physical examinations were performed as the first step of the study. Swabbing of the discharge was then performed. Swab samples from endocervix were obtained using sterile charcoal Amies swab. The swab was rotated for 3 seconds or 3 times. Swab samples in males were obtained by swabbing the urethra from meatal part up to navicular fossa or swabbing the rectum using charcoal Amies swab. Swab samples in charcoal Amies transport medium were stored using ice gel, taken to the Centre of Health Laboratory (Balai Besar Laboratorium Kesehatan [BBLK]) Surabaya in less than 24 hours, and were immediately inoculated in modified Thayer Martin media.

Colonies which grew on modified Thayer Martin media were then examined using Gram staining, catalase, peroxidase, glucose, sucrose, lactose, and maltose tests to identify Neisseria gonorrhoeae bacteria. Colonies confirmed to be Neisseria gonorrhoeae were then re-inoculated in a second modified Thayer Martin media. Colonies which grew in these media were then examined to determine their susceptibility toward cefixime and ceftriaxone using Kirby-Bauer method. The resulting data were collected in forms and were subsequently inputted into the computer. Obtained data were then presented in tables and graphs.

\section{RESULT}

During July 2018 - October 2018, there were 70 patients with complaints of discharge visited the Outpatient Clinic of Dermatology and Venereology Department at RSSA Malang. A total of 31 patients fulfilled the study inclusion and exclusion criteria. Out of 31 swab samples from patients' discharge inoculated into the first batch of modified Thayer Martin media. There were 26 positive colony isolates, which were examined using Gram staining. The 26 positive colony isolates were confirmed to be Neisseria gonorrhoeae. These positive isolates were subsequently inoculated into the second batch of modified Thayer Martin media, and all of them underwent susceptibility testing for cefixime and ceftriaxone.

Baseline characteristics of study subjects can be seen in Table 1. The proportion of gonorrhea patients who seek treatment in the clinic were dominated by males $(96.15 \%)$, the most of the patients were aged 17 -25 years old $(65.38 \%)$ and unmarried $(73.07 \%)$.

Most subjects were residents of Malang city (42.31\%). The most common sexual orientation were heterosexuals $(57.69 \%)$, followed by male homosexuals (30.76\%), and bisexuals (11.53\%). Human Immunodeficiency Virus (HIV) infection status has been examined on the majority of the study subject, and most were non-reactive (80.77\%).

Clinical manifestations of the subjects are shown in Table 2. The discharge was commonly originated from the urethra $(92.31 \%)$, followed by anal fistula and cervix (each was 3.85\%). History of suspected intercourse occurred mostly in $<1$ week before illness (57.69\%). A history of previous gonorrhea complaints was found in $30.76 \%$ of the subjects. Co-existing syphilis and condyloma acuminata infection were found in $11.54 \%$ and $3.85 \%$ subjects, respectively.

Table 3 shows the history of previous treatment, $38.46 \%$ subjects already received treatment, and $100 \%$ of those subjects consumed unprescribed oral drugs which they bought from pharmacy or drugstores. No subject had a history of treatment by the injection-type drug. Antibiotics were used by $90 \%$ of subjects, and the remaining $10 \%$ were using herbal drugs. Type of drugs used was amoxicillin (11.54\%), ciprofloxacin $(11.54 \%)$, thiamphenicol $(3.58 \%)$, doxycycline 
(3.85\%), ampicillin $(3.85 \%)$, pipemidic acid $(3.85 \%)$, and herbal drugs $(3.85 \%)$.

In this study, 26 isolates which were grown in culture media were obtained. Antibiotic susceptibility testing was subsequently carried out using the KirbyBauer method. The results of antibiotic susceptibility test for cefixime and ceftriaxone against Neisseria gonorrhoeae showed that $80.77 \%$ of isolates were susceptible to cefixime, and $80.77 \%$ of isolates were susceptible to ceftriaxone. Meanwhile, the remaining $19.23 \%$ of isolates were resistant to cefixime, and $19.23 \%$ were resistant to ceftriaxone. The percentages of cefixime and ceftriaxone resistance are presented in graphic 1 .

Table 1. Baseline characteristics of subjects visiting outpatient clinic of Dermatology and Venereology Department at RSSA Malang during July 2018 - October 2018

\begin{tabular}{|c|c|}
\hline Variable & Number $(\%)$ \\
\hline \multicolumn{2}{|l|}{ Sex } \\
\hline Male & $25(96.15 \%)$ \\
\hline Female & $1(3.85 \%)$ \\
\hline \multicolumn{2}{|l|}{ Age Group } \\
\hline $17-25$ years old & $17(65.38 \%)$ \\
\hline $26-35$ years old & $6(23.08 \%)$ \\
\hline $36-45$ years old & $3(11.54 \%)$ \\
\hline \multicolumn{2}{|l|}{ Place of Residence } \\
\hline Malang city & $11(42.31 \%)$ \\
\hline Malang district & $2(7.69 \%)$ \\
\hline Outside Malang & $13(50 \%)$ \\
\hline \multicolumn{2}{|l|}{ Occupation } \\
\hline College student & $6(23.07 \%)$ \\
\hline Private sector employee & $5(19.23 \%)$ \\
\hline Salesperson & $4(15.38 \%)$ \\
\hline Teacher & $2(7.69 \%)$ \\
\hline Security officer & $2(7.69 \%)$ \\
\hline Karaoke staff & $1(3.85 \%)$ \\
\hline Bartender & $1(3.85 \%)$ \\
\hline Construction worker & $1(3.85 \%)$ \\
\hline Staff of Religious Affairs Office & $1(3.85 \%)$ \\
\hline Farmer & $1(3.85 \%)$ \\
\hline Singer & $1(3.85 \%)$ \\
\hline Unemployed & $1(3.85 \%)$ \\
\hline \multicolumn{2}{|l|}{ Education level } \\
\hline Senior high school & $17(65.38 \%)$ \\
\hline Junior high school & $4(15.38 \%)$ \\
\hline Diploma 1 & $1(3.85 \%)$ \\
\hline Bachelor & $3(11.54 \%)$ \\
\hline Master & $1(3.85 \%)$ \\
\hline \multicolumn{2}{|l|}{ Marital status } \\
\hline Married & $7(26.92 \%)$ \\
\hline Unmarried & $19(73.07 \%)$ \\
\hline \multicolumn{2}{|l|}{ Sexual orientation } \\
\hline Heterosexual & $15(57.69 \%)$ \\
\hline Homosexual male & $8(30.76 \%)$ \\
\hline Bisexual & $3(11.53 \%)$ \\
\hline \multicolumn{2}{|l|}{ HIV status } \\
\hline Non-reactive & $21(80.77 \%)$ \\
\hline Reactive & $3(11.54 \%)$ \\
\hline Unchecked & $2(7.69 \%)$ \\
\hline
\end{tabular}


Table 2. Clinical manifestations of subjects visiting outpatient clinic of Dermatology and Venereology Department at RSSA Malang during July 2018 - October 2018

\begin{tabular}{lc}
\hline \multicolumn{1}{c}{ Clinical Manifestations } & Number (\%) \\
\hline Discharge origin & $24(92.31 \%)$ \\
Urethra & $1(3.85 \%)$ \\
Anal fistula & $1(3.85 \%)$ \\
Cervical & \\
Discharge consistency & $25(96.15 \%)$ \\
$\quad$ Mucopurulent & $1(3.85 \%)$ \\
$\quad$ Seropurulent & \\
External urethral orifice & $24(92.31 \%)$ \\
$\quad$ Ectropion, erythema, and edema & \\
Duration of symptoms & $1661.54 \%)$ \\
$\quad<1$ week & $5(19.23 \%)$ \\
1 week & $5(19.23 \%)$ \\
$>1$ week & \\
History of the suspected intercourse & $15(57.69 \%)$ \\
$\quad<1$ week & $7(26.92 \%)$ \\
1 week & $4(15.38 \%)$ \\
$>1$ week & \\
Previous history of gonorrhea & $8(30.76 \%)$ \\
Yes & $18(69.24 \%)$ \\
No & \\
Other co-existing STI & $3(11.54 \%)$ \\
Syphilis & $1(3.85 \%)$ \\
Condyloma acuminata & $22(84.61 \%)$ \\
Absent & \\
\hline
\end{tabular}

Susceptibility to ceftriaxone and cefixime was assessed based on clinical manifestations and risk factors (Table 4). Antibiotics susceptibility in subjects without previous treatment was $81.25 \%$ for ceftriaxone and $68.75 \%$ for cefixime; while in subjects who had received prior treatment, the percentage of susceptibility was $80 \%$ for ceftriaxone and $100 \%$ for cefixime. Antibiotics susceptibility in subjects who had never been infected with gonorrhea was $76.47 \%$ for ceftriaxone and $76.47 \%$ for cefixime; while in subjects who had previously been infected with gonorrhea, the percentage of susceptibility was $88.89 \%$ for ceftriaxone and $88.89 \%$ for cefixime. Among HIV-reactive subjects, susceptibility to ceftriaxone and cefixime were each $66.67 \%$, meanwhile, among non-reactive HIV subjects, susceptibility to ceftriaxone and cefixime were each $80.95 \%$.

Table 3. Prior history of treatments at outpatient clinic of Dermatology and Venereology Department at RSSA Malang during July 2018 - October 2018

\begin{tabular}{lc}
\hline History of Treatment & Number (\%) \\
\hline Prior History of Treatment & $10(38.46 \%)$ \\
$\quad$ Treated & $16(61.54 \%)$ \\
Untreated & $10(100 \%)$ \\
Prior Routes of Drug Administration & $0 \%$ \\
$\quad$ Oral & \\
$\quad$ Intramuscular & $10(100 \%)$ \\
Origin of Prior Treatment & $0 \%$ \\
$\quad$ Buying drugs without prescription in pharmacy or drugstore & \\
Prescribed & $9(90 \%)$ \\
Type of Drugs Used & $1(10 \%)$ \\
$\quad$ Antibiotics drugs & \\
Herbal drugs &
\end{tabular}




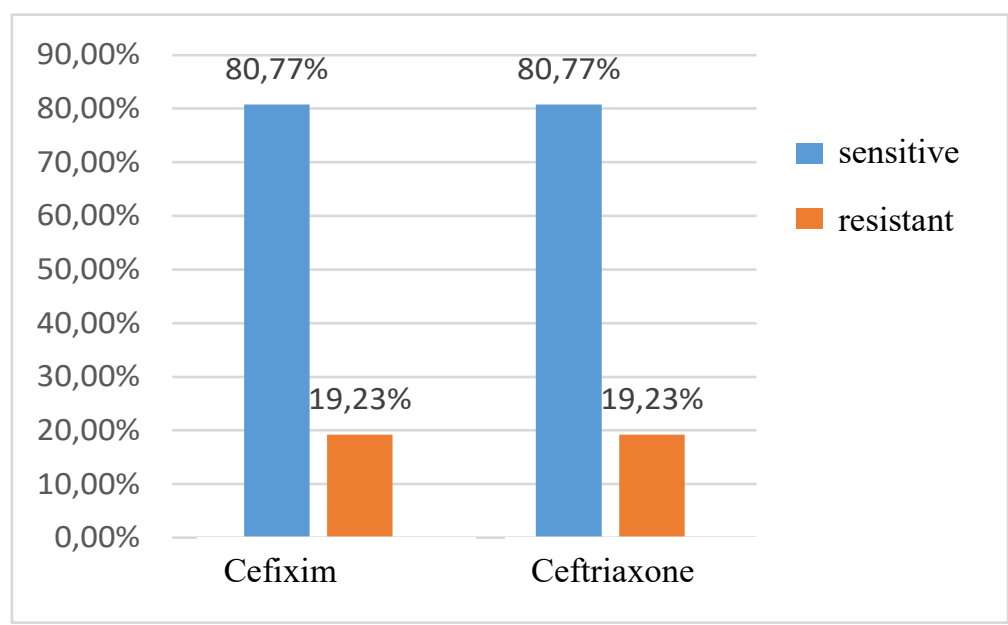

Graphic 1. Cefixime and ceftriaxone susceptibility of Neisseria gonorrhoeae isolates at outpatient clinic of Dermatology and Venereology Department at RSSA Malang during July 2018 - October 2018.

The most common risk factor for gonorrhea infection was heterosexuality. One of the high-risk groups mentioned in the Integrated Biological homosexuality. The estimated risk for a homosexual male to be infected with gonorrhea in the survey Behavior Survey of 2015 was male was $12.72 \%$ lower than the results of this study. ${ }^{12}$

Table 4. Cefixime and ceftriaxone susceptibility of Neisseria gonorrhoeae isolates based on clinical manifestations and risk factors at outpatient clinic of Dermatology and Venereology Department at RSSA Malang during July 2018 - October 2018

Clinical manifestations and risk factors

Susceptibility

\begin{tabular}{lcc} 
& Ceftriaxone & Cefixime \\
\cline { 2 - 3 } Duration of symptoms & $17(80.95 \%)$ & $18(85.71 \%)$ \\
$\leq 1$ week $(\mathrm{n}=21)$ & $4(80.00 \%)$ & $3(60.00 \%)$ \\
$>1$ week $(\mathrm{n}=5)$ & & \\
History of prior treatment & $13(81.25 \%)$ & $11(68.75 \%)$ \\
$\quad$ Untreated $(\mathrm{n}=16)$ & $8(80 \%)$ & $10(100 \%)$ \\
Treated $(\mathrm{n}=10)$ & & $13(76.47 \%)$ \\
History of previous gonorrhea infection & $13(76.47 \%)$ & $8(88.89 \%)$ \\
No $(\mathrm{n}=17)$ & $8(88.89 \%)$ & $12(80 \%)$ \\
Yes $(\mathrm{n}=9)$ & $12(80 \%)$ & $6(75 \%)$ \\
Risk factor & $6(75 \%)$ & $3(100 \%)$ \\
Heterosexual $(\mathrm{n}=15)$ & $3(100 \%)$ & $17(80.95 \%)$ \\
Homosexual male $(\mathrm{n}=8)$ & & $2(66.67 \%)$ \\
Bisexual $(\mathrm{n}=3)$ & $17(80.95 \%)$ & $2(100 \%)$ \\
HIV status & $2(66.67 \%)$ & $2(100 \%)$ \\
Non-reactive HIV $(\mathrm{n}=21)$ & & \\
Reactive HIV $(\mathrm{n}=3)$ & & \\
Unchecked $(\mathrm{n}=2)$ & & \\
\hline
\end{tabular}

$\mathrm{HIV}=$ human immunodeficiency virus

\section{DISCUSSION}

The increase in resistance of Neisseria gonorrhoeae to certain antibiotics has been reported in several studies in Indonesia and other countries. Guidelines from the Centers for Disease Control and Prevention in 2015 did not recommend cefixime as the primary therapy for gonorrhea due to numerous reports of resistance in several countries. ${ }^{4}$ The study was conducted to determine the cefixime and ceftriaxone susceptibility pattern of Neisseria gonorrhoeae isolates in RSSA Malang.

Gonorrhea is currently still a common infection in the community. In the Outpatient Clinic of Dermatology and Venereology Department at RSSA 
Malang, gonorrhea ranked the $5^{\text {th }}$ of all the STI cases. This study also determined other STI risk factors which coincided with gonorrhea infection, one of which was HIV infection (9.4\%) and male homosexuality (18.8\%) in study subjects.

Gonorrhea infection or other STIs can serve as risk factors which influence HIV transmission. Weire et al. found that female sex workers infected with HIV who participated in his study had also previously been infected with gonorrhea. ${ }^{13}$ The risk of HIV infection and gonorrhea in homosexual male risk group is caused by insufficient lubrication in the rectal region, thus rendering higher risk for microlesion. Furthermore, the absorption rate in the area is greater, thereby increasing the risk of transmitting HIV or other STIs. Neisseria gonorrhoeae infection may also induce the production of cytokines and chemokines in monocytes and modulates $\mathrm{T}$ cell activation. In vivo studies showed an increase in the number of CD4+ $\mathrm{T}$-Cells in the endocervical region of gonorrheainfected subjects (CD4+ T-cell is a target cell for HIV infection). ${ }^{14}$ Bernstein et al. conducted a study on male homosexuals who suffered from gonorrhea and chlamydia in the rectal region and suggested that those who previously had two histories of rectal infections will have an 8-fold higher risk for HIV infection. ${ }^{15}$

Suspected intercourse in the study subjects mostly occurred in less than one week preceding the symptoms. This is in accordance with several works of literature which state that the suspected intercourse in gonorrhea patients occurred $2-5$ days preceding the symptoms, ${ }^{16,17}$ whereas, in female patients, symptoms often occur approximately 10 days after infection. ${ }^{18}$ History of recurrent gonorrhea infection was found in $30.76 \%$ of subjects. Brooks et al. revealed that $29.4 \%$ of cases of gonorrhea were reported to occur more than once, especially in the younger age group, which is associated with higher rates of sexual activity and a higher risk of having multiple sexual partners. In addition, the risk of recurrence is also found especially in the male homosexual group. ${ }^{18}$ Study in Thailand found that $40.3 \%$ of their male homosexual subjects had a history of recurrent gonorrhea infection that $68.7 \%$ of them had recurrent infections in the urethra, $6.8 \%$ of them had recurrent infections in the rectum, and $25 \%$ of them had recurrent infections in the rectum and urethra. ${ }^{19}$

An increase in resistance of Neisseria gonorrhoeae is associated with improper selection of drug, drug dosage, and duration of drug administration. In this study, $34.61 \%$ of the study subjects had previously received treatment. Previously consumed antibiotics were also found from other classes of antibiotic, which were not recommended for gonorrhea therapy as high levels of resistance and inappropriate duration of drug administration have been reported. ${ }^{20}$

Susceptibility test results showed that $80.77 \%$ of isolates were still susceptible to cefixime and ceftriaxone, whereas $19.23 \%$ had decreased susceptibility to cefixime and ceftriaxone. A study conducted in Surabaya by Setyaningrum et al. found that $33.3 \%$ of their isolates were resistant to cefixime, and $66.7 \%$ were susceptible to cefixime. ${ }^{22}$ Another study by Pidari in Denpasar showed that out of 45 obtained isolates, $51.2 \%$ were susceptible to cefixime and $48.8 \%$ had decreased susceptibility. ${ }^{7}$ The results of this study were in contrast with the study of Hananta et al. conducted in three major cities in Indonesia (Jakarta, Yogyakarta and Denpasar), in which out of 79 urogenital culture isolates, all isolates were found to be $100 \%$ susceptible to ceftriaxone and cefixime. On the contrary, the isolates were found to be mostly resistant to doxycycline $(98.7 \%)$ and ciprofloxacin (97.4\%). ${ }^{6}$ Saroh's study in Semarang showed that $77 \%$ of samples were resistant and only $23 \%$ were susceptible to ceftriaxone. ${ }^{8}$ The results of this study indicate that the susceptibility of Neisseria gonorrhoeae towards cefixime and ceftriaxone in RSSA is still higher compared to studies in other cities in Indonesia.

Factors which caused cefixime and ceftriaxone resistance found in this study cannot be ascertained because it may be influenced by many factors, such as changes in penB, mtrR, and penC genes as well as mutations in penA genes in PBP2. The disrupted penA gene may result from mutations or genetic recombination. ${ }^{22,23}$ Changes in PBP2 encoded by the penA gene are the cause of decreased binding to penicillin through a single insertion of amino acids. This change was also found in cephalosporinresistant isolates. ${ }^{24}$ Further evaluation is needed to determine the significance of the possible causes of decreased susceptibility to cefixime and ceftriaxone in this study. Limitation of this study was associated with the chosen antibiotic susceptibility testing method, which is the Kirby Bauer method, as it is not the current gold standard method for assessing the susceptibility of antibiotics. The gold standard for antibiotic susceptibility testing is by agar dilution method to quantitatively determine the Minimum Inhibitory Concentration (MIC) (pg/ml). ${ }^{22}$

The results of antibiotic susceptibility test for cefixime and ceftriaxone against Neisseria gonorrhoeae showed that $80.77 \%$ of isolates were susceptible to cefixime, and $80.77 \%$ of isolates were susceptible to ceftriaxone. Meanwhile, the remaining 
$19.23 \%$ of isolates were resistant to cefixime, and $19.23 \%$ were resistant to ceftriaxone. As conclusion, cefixime and ceftriaxone are still effective as gonorrhea therapy in RSSA Malang.

\section{REFERENCE}

1. Tapsall J.W, Ndowa F, Lewis D.A, Unemo M. Meeting the Public Health Challenge of Multidrug and Extensively Drug-Resistant Neisseria gonorrhoeae. Expert Rev Anti Infect Ther 2009; 7: 821-34.

2. Unemo M, Nicholas RA. Emergence of Multidrug-Resistant Extensively Drug-Resistant and Untreatable Gonorrhea, Future Microbiol 2012; 7(12):1401-22.

3. World Health Organization. Global Incidence and Prevalence of Selected Curable Sexually Transmitted Infections. Geneva: WHO Press; 2012.

4. Center for Diseases Control and Prevention (CDC). Sexually Transmitted Disease Surveillance 2016, Division of STD Prevention. Atlanta: CDC; 2017.

5. World Health Organization. Global Action Plan to Control the Spread and Impact of Antimicrobial Resistance in Neisseria gonorrhoeae. Geneva: WHO Press; 2008.

6. Kementerian Kesehatan Republik Indonesia. Pedoman Nasional Penanganan Infeksi Menular Seksual. Jakarta: Kementerian Kesehatan Republik Indonesia; 2015.

7. Ohnishi M, Golparian D, Shimuta K, Saika T, Hoshina S, Iwasaku K, et al. Is Neisseria Gonorrhoeae Initiating a Future Era of Untreatable Gonorrhea: Detailed Characterization of the First Strain with HighLevel Resistance to Ceftriaxone, Antimicrob Agents Chemother 2011; 55:3538-45.

8. Unemo M, Golparian D, Nicholas R, Ohnishi M, Gallay A \& Sednaoui P. High-level cefixime-and ceftriaxone-resistant Neisseria gonorrhoeae in France: novel penA mosaic allele in a successful international clone causes treatment failure. Antimicrob Agents Chemother 2012; 56(3) :1273-80.

9. Hananta I. P. Y, van Dam A. P, Bruisten S. M, van der Loeff M. F. S, Soebono H, \& de Vries H. J. C. Gonorrhea in Indonesia: high prevalence of asymptomatic urogenital gonorrhea but no circulating extended spectrum cephalosporinsresistant Neisseria gonorrhoeae strains in Jakarta, Yogyakarta, and Denpasar, Indonesia. Sex Transm Dis 2016; 43(10): 608-16.
10. Saroh DUM, Muslimin M, Hadi P. Uji Beda Sensitivitas Seftriakson Dengan Levofloksasin pada Kuman Neisseria gonorrhoeae secara in Vitro. JKD 2016; 5(4): 1-7.

11. Patel J.B, Weinstein M.P, Eliopulous G.M, Jenkins S. G, Lewis J.S, Limbago B, et all. Clinical and Laboratory Standards Institute M100- Performance Standards for Antimicrobial Susceptibility Testing. $\quad 27^{\text {th }}$ ed. Pennsylvania: Clinical and Laboratory Standards Institute; 2018

12. Kementerian Kesehatan Republik Indonesia. Surveilans Terpadu Biologis dan Perilaku; 2015. Available from: URL: http://www.P2P. kemkes.go.id.

13. Weir S. S, Feldblum P. J, Roddy R. E, \& Zekeng L. Gonorrhea as a risk factor for HIV acquisition. AIDS 1994; 8(11): 1605-8.

14. Jarvis G, L Chang T. Modulation of HIV transmission by Neisseria gonorrhoeae: molecular and immunological aspects. Current HIV research 2012; 10(3): 211-7.

15. Bernstein K. T, Marcus J. L, Nieri G, Philip S. S, \& Klausner J. D. Rectal Gonorrhea and Chlamydia Reinfection is Associated with Increased Risk of HIV seroconversion. JAIDS 2008; 53(4): 537-43.

16. Murlistiastutik D. Gonorrhea pada Pria. Dalam: Barakbah J, Lumintang H, Martodiharjo S, editor. Buku Ajar Infeksi Menular Seksual. Surabaya: Airlangga University Press; 2008. h. 109-14.

17. Hook E. W, Handsfield H. H. Gonococcal Infections in The Adult. In: Holmes K, Sparling P, Stamm W, Piot P, Wasserheit J, Corey L, et al, editors. Sexually transmitted diseases. $4^{\text {th }}$ ed. New York: McGraw-Hill; 2008. p. 627-45.

18. Brooks G. F, Darrow W. W \& Day J. A. Repeated Gonorrhea: An Analysis of Importance and Risk Factors. JID 1978; 137(2): 161-9.

19. Pattanasin S, Luechai P, Sriporn A, Tongtoyai J, Sukwicha W, Kongpechsatit O, Sirivongrangson P, Holtz T.H, Curlin M.E, Dunne E.F. Factors associated with repeat symptomatic gonorrhea infections among Men Who Have Sex with Men. J Med Assoc Thai 2018; 91: 1-19

20. Costa-Lourenco A P R D, Santos K T B D, Moreira B. M, Fracalanzza S E L, Bonelli, R R. Antimicrobial Resistance in Neisseria gonorrhoeae: History, Molecular Mechanisms and Epidemiological Aspects of an Emerging Global Threat. BJM 2017; 48(4): 617-28.

21. Setyaningrum $T$, Astindari A, Lumintang $H$. Sensitivity Difussion Test of Cefixime against Neisseria gonorrhoeae from Female Sex Worker with Cervicitis Gonorrhea without Complication 
Who Follow Periodic Presumptive Treatment (PPT). Berkala Ilmu Kesehatan Kulit dan Kelamin. 2017; 29(1): 65-72.

22. Unemo M, Shafer W.M. Antimicrobial Resistance in Neisseria gonorrhoeae in the 21st Century: Past, Evolution, and Future. Clin Microbiol Rev 2014; 27(3):587-613.

23. Ameyama S, Onodera S, Takahata M, Minami S, Maki N, Endo K, et al. Mosaic-Likestructure of
Penicillin-Binding Protein 2 Gene (PenA) Inclinical Isolates of Neisseria gonorrhoeae with Reduced Susceptibility to Cefixime. Antimicrob Agents Chemother 2002; 46(12):3744-49.

24. Barry P.M, Klausner J.D. The Use of Cephalosporins for Gonorrhea: The Impending Problem of Resistance. Expert Opin Pharmacother 2009; 10(4):555-77. 